University of Wollongong

Research Online

Faculty of Social Sciences - Papers (Archive) Faculty of Arts, Social Sciences \& Humanities

2017

Student isolation: the experience of distance on an international field placement

Mim Fox

University of Wollongong, mfox@uow.edu.au

Follow this and additional works at: https://ro.uow.edu.au/sspapers

Part of the Education Commons, and the Social and Behavioral Sciences Commons

Research Online is the open access institutional repository for the University of Wollongong. For further information contact the UOW Library: research-pubs@uow.edu.au 


\title{
Student isolation: the experience of distance on an international field placement
}

\author{
Abstract \\ In an era of global awareness of the impact of social, political and environmental impact, the international \\ field placement has become a feature of many social work programmes throughout Australia. A \\ theoretical framework of international social work principles allows for a guiding platform for teaching \\ and learning; however, the experience of the social work student is often one of cultural isolation and \\ emotional vulnerabilities. Whilst cross-cultural learning is a core practice goal of the placement, the ability \\ to engage with this learning is affected by the impact of distance on the student. In turn, the university \\ responsibility for the student is heightened by the distance involved, creating an increased sense of risk \\ for both the student and the social work educator. This article draws on a mixed-methods study, with data \\ sourced from both questionnaires and in-depth interviews with university field education staff, former \\ social work students, and field educators. Five lenses of distance are explored in the aim of increasing \\ understanding of the student experience: geographical distance, cultural distance, emotional distance, \\ pedagogical distance and technological distance. In doing so, the social work educators' ability to \\ monitor and support remote students is enhanced, and the capacity for the student to engage in a \\ positive teaching and learning environment is increased.

\section{Keywords} \\ student, distance, placement, isolation:, experience, international, field \\ Disciplines \\ Education | Social and Behavioral Sciences \\ Publication Details \\ Fox, M. (2017). Student isolation: the experience of distance on an international field placement. Social \\ Work Education, 36 (5), 508-520.
}


Student isolation: the experience of distance on an international field placement

\section{Key words}

International field placement, distance, social work student, social work education, isolation, vulnerability

\section{Acknowledgements}

The author would like to acknowledge Social Work Education- the international journal for the SWERSA Scholarship for PhD Completion. 


\section{Abstract}

In an era of global awareness of the impact of social, political and environmental impact, the international field placement has become a feature of many social work programs throughout Australia. A theoretical framework of international social work principles allows for a guiding platform for teaching and learning, however the experience of the social work student is often one of cultural isolation and emotional vulnerability. While cross-cultural learning is a core practice goal of the placement, the ability to engage with this learning is affected by the impact of distance on the student. In turn, the university responsibility for the student is heightened by the distance involved, creating an increased sense of risk for both the student and the social work educator. This article draws on a mixed methods study, with data sourced from both questionnaires and in-depth interviews with university field education staff, former social work students, and field educators. Five lenses of distance are explored in the aim of increasing understanding of the student experience: geographical distance, cultural distance, emotional distance, pedagogical distance and technological distance. In doing so, the social work educators ability to monitor and support remote students is enhanced, and the capacity for the student to engage in a positive teaching and learning environment is increased. 


\section{Student isolation: the experience of distance on an international field placement}

International field placements have emerged as an extension of the traditional field education relationship, whereby social work students engage in practice learning at an agency separate to the university, under the supervision of a qualified social worker. For the international field placement, this relationship poses additional challenges in that students are travelling remotely for long periods of time with limited monitoring or support from their home university. The international literature is slowly growing with an understanding of the lived experience of the student on the international field placement, yet is still compartmentalised in its understanding. Each social work student on an international field placement experiences distance in a unique way, requiring an advanced conceptualisation of the notion to inform social work educators' in this field.

In this study, "field educators" refer to agency-based social workers who undertake regular supervision with students throughout their international field placement. The "social work educator" is an umbrella term for field educators and field education staff members employed by universities.

\section{Background to the research}

In recent years international field placements have become fashionable in social work programs across the world (Razack, 2002), with the inclusion of experiential international learning being common globally (Pettys et al., 2005). This momentum has gathered speed in recent years alongside the global debate regarding the universality and applicability of global social work principles (Sewpaul \& Jones, 2004). Globalisation provides a context for international social work with the individual and community impact increasingly encompassing all areas of human existence (Hokenstad \& Midgley, 1997; Stiglitz, 2007; Lyons et al., 2006; Hugman, 2010), and is cited as a key factor in this increase of international study (Panos, 2005). 
Whilst globalisation is able to provide a context for this learning, social work students are able to link global social issues with the everyday impact on the individual, resulting in the practice of international social work intervention to be engaged with both in the classroom and on field placements (Cornelius \& Greif, 2005). Writers have acknowledged the global changing nature of the welfare state (Romanov \& Kononenko, 2014), the capacity for social workers to cross borders in their practice (Razack, 2002), and the role of social work as a profession of capability in this field (Lyons et al., 2006). The need and capacity for social workers to intervene proactively with the client groups affected by globalisation makes the provision of an international field placement in modern social work training acutely relevant (Nagy \& Falk, 2000; Hugman, 2010).

The literature discusses the development and internalisation of social work virtues as the basis of the development of an international social worker (Pullen-Sansfacon et al., 2012), with a critical awareness of the challenges of ethno-centrism (Engstrom and Jones, 2007). For social work practice, the benefits of an international field placement include experiencing different systems of welfare and different perspectives on addressing social issues (Healy, 2008), while in countries with limited diversity in local placements, the provision of international field placements offers an opportunity to practice and build cross cultural skills (Saito and Johns, 2009). In addition writers argue for the development of culturally sensitive world leaders (Boyle et al., 1999) and the preparation of students for working in an interdependent world (Pettys et al., 2005) and global labour market (Healy, 2008).

Global literature regarding the prevalence of international field placements in social work education has increased over the last 30 years (Dominelli and Bernard, 2003; Healy, 2008). The international field placement allows students to learn about international social work whilst practicing it, a practice that encompasses cross-cultural skills and anti-colonialist practice (Razack, 2002; Gray, 2005). This learning stems from a state of cultural disconnection, or cultural ambiguity (Barlow, 2007), supported by an integrated program 
where structured learning opportunities that surround the experience are combined with the aim of intercultural competence (Rotabi et al., 2006).

Current international writers describe the educational support to students on an international field placement as being crucial. They state that international field placements should not be attempted without adequate preparation, debriefing, and an emphasis on cross-cultural learning by both the university and the student (Barlow, 2007; Healy, 2008). Ideally within this pre-placement preparation, there is shared information about the placement location, history, and culture (Boyle et al., 1999), as well as an orientation to indigenous social work practice, pertinent legal constraints in the region, and practical departure assistance (Pettys et al., 2005). The success of an international field placement can be determined by reviewing the organisational infrastructure and arrangements, the students' motivation and background, including financial, the student's preparation prior to departure, the quality of the supervision the student receives whilst on placement, and the support system in place for the student whilst on placement (Rai, 2004).

What is currently lacking, in both the Australian and international literature, are statistics on the provision and organisation of international field placements from Australian social work programs. The recent Australian literature discusses either the quality of the experience itself (Cleak and Fox, 2011; Garrity, 2011; Nickson et al., 2009) or refers to the existence of these placements without quantifying it (Noble et al., 2009; Noble \& Henrickson, 2011; Bell and Anscombe, 2013). In line with the international literature, there is an agreement as to the need for educational support to be provided across the spectrum of the duration of the international field placement, ranging from pre-placement to post-placement (Tesoriero and Rajaratnam, 2001), and that the minimum level of support is contact with the student during the course of the international field placement itself (Garrity, 2011; Bell and Anscombe, 2013).

\section{Methodology}


The findings reported on in this article are sourced from a doctoral study that explored the teaching and learning experience of the international field placement. The study utilised a mixed methods methodology in two stages. In the first stage, a questionnaire was sent to all social work programs in Australia, with the aim of gathering data regarding the provision of international field placements. The questionnaire was sent to those employed by qualifying social work programs at Australian universities that worked directly with the provision of field placements to enrolled social work students. Potential key informants included professors or directors of field education, heads of social work programs or coordinators of international field placements, and could be either academic or professional staff (staff employed in either administrative or non-academic managerial roles). Participants were recruited using purposive sampling identified through public sources such as university websites, or through the contacting of administrative positions at the various universities. Of the 28 questionnaires sent to social work programs in universities across Australia, 22 responses were received (79\%). A total of 15 programs indicated that they participated in at least one aspect of international field placements, that is sending Australian social work students to other countries, or receiving international students from overseas universities for the purposes of an international field placement. The questionnaire consisted of both quantitative (demography) and qualitative (open questions) data. Attempts were made to follow up with social work programs that did not respond for the inclusion in the second stage of data collection.

In the second stage, in-depth interviews were conducted with a sample group consisting of field education staff working currently in social work programs throughout Australia, field educators in Australian agencies that had supervised international students on field placements as part of their substantive positions over the previous 10 years, and former students that had undertaken international field placements as part of their qualifying social work program in the previous 10 years. In this stage, participants were recruited using a combination of snowball and purposive sampling. In total, 15 interviews with university field education staff were conducted, two of which 
were from the same university. All Australian states and territories were represented in the interviews, with the participants ranging from academic staff to those in professional positions. Flexibility was given to encourage participation, including the conducting of interviews on site at the participating universities. At the request of participants, three social work program interviews were conducted remotely, and one interview was conducted in two separate meetings. The interview guide did not vary between these occasions. Throughout the interviews, university participants discussed the various countries they received or sent students to on international field placements including Sweden, India, Norway, Argentina, Germany, Ireland and Cambodia.

10 interviews were conducted with former students. The students were sourced from three separate universities across Australia, with the majority having studied in the state of New South Wales, a minority having studied in South Australia, and one participant having studied in Victoria. The students had undertaken their international field placements in Sweden, India, South Africa, Fiji, Myanmar and Kiribati. Nine interviews were conducted with field educators. Each of the field educators interviewed had worked in agencies in Australia when they supervised international students from overseas universities on field placements in Australia. The majority of field educators interviewed were working in the Health sector, while the minority were in nongovernment organisations. The countries the field educators had received students from were primarily Sweden, Norway and India. Flexibility was again provided to encourage participation, with both students and field educators choosing the venue for their interviews. The majority of students were interviewed at either a university, or in a public space. The majority of field educators were interviewed at their current work place in a confidential space.

For the purpose of this research, student participants were limited to students who travelled with the specific aim of undertaking an international field placement. The experiences of international students, those undertaking their entire degree in Australian universities, were not included in the study and their experiences of field placements would benefit from being the subject of 
further research. In addition, the students interviewed were primarily from two States, and therefore were not representative of all of the Australian states and territories.

The findings reported on in this article were primarily analysed from the indepth interviews, utilising a semi-structured interview guide. Ethics approval was gained from the University of New South Wales Human Research Ethics Committee for this study initially in $\mathbf{2 0 0 9}$ and data analysis was complete in 2012.

\section{Findings}

A repeated theme in this study across participant sample groups was the importance attributed to distance on an international placement, and the unique lens through which distance was being viewed. Ultimately what unites these experiences is the meaning the individual attaches to the lived experience. The common denominator within distance, across the sample groups, is the feeling of isolation in a learning environment, of being the "other" in a cross-cultural setting, and of problem solving that experience with educational support. Writers have referred to cultural differences on international field placements (Razack, 2002; Engstrom \& Jones, 2007), and methods used to reduce isolation (Kleinpeter \& Potts, 2004; Panos, 2005). However the literature does not address the range of experiences that distance allows for, and the impact of these various forms of distance on students, field educators and university staff. In order to inform an understanding of the student's lived experience of an international field placement, and the educational support and input provided, distance can be understood in five ways: geographical, cultural, emotional, pedagogical and technological.

\section{Geographical distance}

As industry has felt the effects of globalisation, so has the higher education sector. The motivations of universities to include the provision of international 
field placements in their social work offerings stems from a now common underlying philosophy of internationalisation (Dominelli, 2014), a popular change brought about by the emphasis on global communications and partnerships. The majority of university staff when interviewed discussed a link between the university's mission statement or pedagogical emphasis and whether there was university-wide support for an international educational experience. Whether a university has an overt agreement, or mission statement, regarding a philosophy of global partnership allows a social work program the ability to pursue an agenda of internationalisation, including being able to offer international field placements. Despite this trend, the increase in awareness of global political and social issues has brought about a parallel rising awareness regarding the physical safety and risk that students undertake when travelling across the globe.

Geographical distance is particularly pertinent to Australian students given that when an Australian student travels internationally, or an overseas student comes to Australia, they are generally travelling a large distance and are then many hours flight away from their home. This geographical distance has implications for the emotional experience of the student should they become homesick, have problems with the progression of their placement, or if the student has invested a large amount of money to undertake the placement. In addition there are concerns about the physical and emotional safety of the student, culminating in a heightened sense of responsibility from the social work educators.

Descriptions of student vulnerability, assumptions regarding students' practical and emotional needs, and the relaxation of professional boundaries were demonstrated in the study as inclusive in the educator role. These aspects are demonstrated through the facilitation of connection with the student's home country, minimising the student's sense of emotional distance by facilitating local networks and culturally specific networks, and being a tour guide in the new city and country that the international field placement is located in. Examples provided include helping students to communicate with family online from computers in the agency, taking students to local 
community groups or churches to facilitate local connection, taking students on day trips to local tourist spots, or facilitating interstate travel to allow the student to see more of Australia.

In the Australian context, the supervision for social work students on both local and international field placements is mandated in the Australian Social Work Education and Accreditation Standards, and requires a minimum of 1.5 hours supervision per student for each five days of placement (AASW, 2010). Social work educators emphasised the need to prioritise these requirements when organising international field placements and discussed the extent to which university staff go to ensure compliance occurs. However, there were instances where this did not occur and the very real implications were then evident for the wellbeing of the student.

In Banda Aceh I couldn't get any supervision because of the distance. All I did was to write my journals and my supervisor [university liaison] would read the journals and that's about it [...] when I went back to Singapore I had three weeks of break because of my visa and that was when I had phone-to-phone contact with my supervisor [university liaison], [...] when I was back in Singapore for three weeks I felt exhausted, burnt out (Student 9).

Determining and monitoring the level of risk was a recurrent theme when discussing university concerns, and student insurance was highlighted as an area where university field education staff members need to actively advocate for what can be seen as potentially risky situations in non-mainstream educational experiences. One university staff member discussed the experience of a student being at risk in an international setting, the personal sense of responsibility that emerged for them, and the implication on their capacity to support future international field placements.

My reservation [for future international placements] stems from one girl going to Sri Lanka and she was there when the tsunami hit [...] We had a connection with the agency and with a university and she knew the 
agency and she knew someone she could stay with [...] Then when the tsunami came in, I had no way of knowing whether she was ok or not, for about 3 weeks. I was sitting there thinking, 'I've sent this student to their doom' (University Staff 2).

By specifically focusing on geographical distance and understanding the meaning that it holds for those involved in an international field placement, we are able to begin to understand the importance of concepts such as risk management, student vulnerability, and educational responsibility. These concepts are not limited to geographical distance and in some ways are enhanced by the presence of other understandings, such as cultural distance.

\section{Cultural distance}

As previously discussed, cross-cultural learning is a core practice skill that a student is required to engage with on an international field placement, and integral to the international social work teaching and learning framework. Australian values held by the student or social work program, can be at odds with other cultural perspectives and understandings, and can emerge as an experience of cultural distance, or cultural clash. Cultural clash is global in its experience, is applicable to both students and educators (Bartoli et al. 2008; Holtzhausen, 2011), and culminates in creating a sense of "other" in the nonnative. Not speaking the local language, not eating the local foods or not agreeing with the dominant cultural norms or values can enhance this sense of cultural distance and can become isolating and alienating for the student (Barlow, 2007). In this situation, the student can become dismissive and disrespectful (Quinn, 2009; Nadan and Ben-Ari, 2013), they can stop engaging with support provided to them, or discourage the offerings of support, and ultimately this can have an affect on their overall wellbeing (Harrison \& Ip, 2012).

One student discussed the separation they felt due to their skin colour and the ensuing difficulties they had in communicating empathy with their clients. 
[I was] definitely standing out like a sore thumb, being the only white person for miles around, going into villages where people would bring their kids to me because they've never seen a white person [...] it's quite clear, on a visual level, that I may have had a completely different experience to you [the client], [...] you really can't hide the fact that you need to learn about the other person (Student 7).

Whilst the learning regarding culture is crucial to the international field placement, the interplay between the culture of the student, the culture of the host community, and the educational culture that the student has been previously studying, is challenging. Supervision has been viewed as a creative opportunity to develop the student's cross-cultural learning, specifically by providing an opportunity for analysis of moments of cultural clash (Cooper and Maidment, 2001). A critically reflective process in a crosscultural context can be enhanced through the use of individual cultural autobiographies (Hollinsworth, 2013; Grace et al., 2013), cultural genograms (Warde, 2012), critical incident analysis (Napier, 2006; Das and Anand, 2014), and reflective journal writing (Garrity, 2011).

For some students cultural clash occurred when they were confronted with workplace or organisational norms, such as punctuality. One student describes differing cultural expectations regarding workplace meetings and time management.

That's just their culture, they don't have a time, you organise meetings with them and they just don't turn up [...] I'm a very systems, taskoriented person, so the first few times I was getting so frustrated. So they'd come into work the next day and l'd say, "we had an appointment yesterday, we were supposed to meet" and they'd say, "oh yes, yes". So the next time we'd organise a meeting they didn't turn up for that day, then they just didn't turn up for the next three days in the hope that l'd forgotten that we were supposed to meet up! (Student 8). 
On a broader level, cultural clash could be experienced for students regarding organisational philosophy for client care. In these situations opportunities for boundary testing and in-practice learning often arose.

There was a child-headed family [...] their uncle was meant to be looking after them [...] they were going to have no food for that weekend $[\ldots]$ there was no way to get them food unless I bought it. So for a boundary would be not to buy clients things [...] part of me just went [...] 'I'm a student, I don't care, I'm just going to do it' [...] there's no places to refer someone, it's you or it's no one (Student 7).

Whether cultural distance is felt regarding interpersonal norms such as punctuality, or value based norms such as client wellbeing, the moments of cultural clash can be isolating for the student on the international field placement and can produce a sense of emotional vulnerability. This can translate to an emotional distance where resilience on the part of the student is required.

\section{Emotional distance}

The wellbeing of the student can be impacted by geographical and cultural distance, with the student's capacity to engage in an isolated and vulnerable teaching and learning environment being termed emotional distance. Throughout the study both university staff and field educators discussed the need to screen students prior to their acceptance on an international field placement and a recurrent theme that emerged was the presence of resilience in the student. Resilience is a word used most often in social work therapeutic settings to describe personal strength within a client. However in the literature, resilience in social work students is linked to emotional intelligence and reflective ability, and is seen as a core component of surviving in the social work profession (Grant and Kinman, 2012). In this study, resilience was used by the participants to describe the emotional strength or fortitude of the social work student, and was demonstrated in the student's capacity to cope with uncertainty and to be flexible. In the pre- 
placement phase, having had prior work or travel experiences, or specific skills such as language skills, were seen as indicators of resilience.

Language skills emerged in the study as an important consideration when screening students for resilience, in the aim of minimising their potential isolation and overall wellbeing (Rai, 2004; Crisp, 2009; Harrison and Ip, 2012). Although knowledge of the local language emerged as a common consideration, it does not stand alone as an indicator of resilience as cultural distance can still be present despite language proficiency (Beecher et al., 2012). A lack of language skills can however, have an adverse impact on the success of the placement and the emotional capacity of the student, despite other indicators of resilience being present.

Throughout the study, the participants made reference to the changes that an international field placement brought about in them. One student described their experience in a particularly remote setting, emphasising how their resilience prior to the international field placement helped them in adapting and problem solving throughout.

I survived because of the sort of person I am [...] I'm a strong person who picks myself up and goes 'Right, off we go, no one's at the office today ok [...] Then I found my little friend who I called monkey who used to climb up the frangipani trees and get me flowers so I just thought, you can climb up that hole in the wall couldn't you? Problem solved, in the office I was [...] I just did what I did and learnt and experienced an amazing culture (Student 8).

For all students, the emotional vulnerability and isolation that they experience on an international field placement is a test of their personal resilience. University staff and field educators are acutely aware of the emotional distance that students' experience, and that this can be additionally heightened by a difference in international institutional expectations.

\section{Pedagogical distance}


Pedagogical distance is experienced when university staff negotiate international field placements, when field educators determine their supervisory input to their students on placement, and when students navigate their cross-cultural learning in a distance learning environment. In the Australian context the AASW sets out mandatory requirements for field education courses within qualifying social work programs in Australia and more specifically, dictates the structure, organisation and support provided to these placements. When discussing international field placements the document states that each placement must be assigned 'field education liaison staff' (AASW, 2010) and specifies the method, frequency and mode of this liaison. The level of university contact and content as prescribed to local placements is identical to international placements and the obligation on social work programs is therefore to ensure that all students who undertake an international field placement receive the same level of liaison support as do their local counterparts. How universities organise this differs between programs, but all are in agreement that the liaison contact provided is ideally required across the spectrum of the international field placement, ranging from pre-placement to post-placement, and that the minimum level of liaison support is contact with the student during the course of the placement itself (Garrity, 2011; Bell and Anscombe, 2013). This liaison role is seen as crucial, beginning prior to the student leaving by way of organisational negotiation, cultural preparation for the student, monitoring throughout the placement, and debriefing the student upon return (Barlow, 2007). It can also involve prompt email and phone response to the student, remote supervision and online feedback regarding reflective writing (Nickson et al., 2009). One university staff member in this study described their liaison role as being an overall monitor of the placement itself within a greater social work program.

[l'm] between a liaison visitor and a supervisor, helping them to process things that happen, making contact by email, also making contact by Skype, trying to actually eyeball them whilst they're overseas [...] having phone conversations [...] making sure that the field placement paperwork is all done and their assessments are done 
[...] responding to risk issues that arise so any situations or events that came up that were problematic either from a health perspective or from a trauma or from a learning perspective (University Staff 1 ).

Similar to the local placement, it is not always qualified social workers undertaking the supervision of social work tasks by social work students in the international agency. The range of qualifications that international supervisors have provides a pedagogical challenge for the home university as it weakens the capacity for the home university to monitor the teaching and learning environment, and for the student to make professional links, although it increases the chance for a social work student to have access to a range of learning opportunities while on placement. Given the specified requirements for field placement supervisors in the professional context in Australia, both students and educators are vigilant in their need for clarity in this area. A student on an international field placement in India discussed their need to educate their supervisor in their pedagogical expectations.

It's about trying to get Indian social work and Australian social work to meet in the middle [...] [my supervisor] was sometimes like 'Well, I'm not sure what you expect'. We had to sit down and say 'Ok, we'd like to be able to come to you with our reflections' and he said he'd like to do that (Student 5).

One field educator discussed their frustration at the lack of clarity they received regarding pedagogical expectations from the international home university for their student on an international field placement in Australia.

As the placement kind of carried on we saw that their expectations and what we expect from a final year student was very, very different [...] we couldn't get them to concretely say what the person needed to be able to achieve at the end (Field Educator 2).

Whilst pedagogical distance is a common feature of an international field placement, it is heightened by geographical and cultural distance, and 
alleviated by liaison support. Liaison support however is made difficult by the inequity of access to technology across the globe, leading to a sense of technological distance.

\section{Technological distance}

As previously discussed, there has been an increasing focus amongst the tertiary education sector on internationalisation and risk management. It is the supervisor relationship and liaison support provided to the international field placement that alleviates these concerns by monitoring the physical and emotional wellbeing of the student. That being said, even with both the home university and the overseas hosting university having the intention of minimising the sense of distance a student experiences, it is often the polarised levels of technology that undermine this. Despite the global advances in technology and telecommunication, equitable ease of communication does not exist around the world. When students are travelling from global North countries and are representing global North universities (Pullen-Sansfacon et al., 2012), such as Australia, there can often be an expectation from both students and university staff that the telecommunications available throughout the international field placement will be of a similar standard as in the home country. This is seen similarly in the experience of global North field educators and highlights a clash in expectations for liaison support throughout the placement experience. As one student describes, the technology available can often dictate the amount of liaison support a home university can provide their student.

I think we arranged, from memory, every fortnight to be in some sort of phone contact. Originally it was going to be video conferencing but what we discovered when we were over there is that the broadband, the technology over in South Africa doesn't allow for video conferencing (Student 7). 
One university staff member highlights the impact that technological distance can have on a supervisory relationship with students, and the impact this can have on student conduct when in a remote setting.

Of course they were supposed to also have conversations with him [remote field educator] very regularly, but things would drop out in India all the time and the computers wouldn't work and lots of technological problems and I think the students hid a bit from him [remote field educator] too (University Staff 4).

Whilst supervision and liaison support on the international field placement are dictated to by the Australian professional standards, it is the complication of technological access that can often prevent this from occurring. The result of this is the increased isolation and vulnerability for the social work student undertaking their international field placement.

\section{Discussion}

Despite the popularity of international field placements in the literature in recent years, there is still a gap in regards to the lived experience of social work students' international field placements. The literature primarily focuses on the benefits of a combination of international travel and education, including comparative cross cultural practice. Some studies refer to a sense of isolation in the student, but they do not address the impact on the student, or potential interventions by the social work educators involved. The key findings from this study highlight the intersecting nature of a students' experience of distance, and provide guidance for what intervention social work educators can provide.

Distance as discussed in this article can be seen through five different lenses: geographical, emotional, cultural, pedagogical and technological. Whilst analysing each form of distance in and of itself aids an increased understanding of the student experience, no form of distance stands on it's 
own. They intersect constantly on an international field placement, with an experience of cultural clash or challenge leading to an eventual feeling of isolation in the student. An example could be an Australian student on an international field placement in India experiencing difficulties with internet access, so being unable to contact their home university for support with assessment tasks. Also while undertaking placement tasks they may find it difficult to understand the agency staff's expectations of them, and begin to feel culturally at a loss and socially isolated. In this scenario the student is experienced an intersection between various forms of distance, culminating in a sense of isolation.

Through this understanding of distance social work educators can prepare students specifically with this challenge in mind. When undertaking preplacement preparation with students, university staff can discuss resilience strategies, cultural norms and the challenging context. They can also ensure their, or their colleagues, availability to students throughout the placement in the knowledge that these students are more likely to feel isolated, may have difficult telecommunications access, yet be needing additional support. When advocating for university resources to support these placements, university staff and field educators alike can argue from a position of lived experience, advocating for a higher need based on the student's geographical and emotional distance.

Finally, by seeing distance as an all encompassing experience, social work educators are able to engage with both students and international field educators in a more nuanced and meaningful way. When students experience moments of cultural clash or social isolation, social work educators can be informed regarding the ever present sense of this isolation and "otherness" on the part of the student, and the student's feeling of vulnerability that undertaking an international field placement can produce.

\section{Conclusion}


An expanded understanding of the notion of distance allows for an engagement with the lived experience of the social work student on the international field placement in a deeper and more empathic way. That in turn leads us to question our practices as social work educators in the preparation, educational and emotional support, and professional re-integration of these students upon return. The responsibility for the monitoring of the emotional and practical safety of the student is still grounded in the collegial relationships, and sometimes legal documentation, which underpins these international arrangements. Historically, this is reminiscent of the collegial relationships that are ingrained in field education. However, for the social work student who is isolated and vulnerable in an international setting there is a greater responsibility required. By acknowledging the various forms of distance we are able to pay attention to the needs of the students who are geographically far away, being immersed in a culturally alien environment, experiencing emotional fragility whilst drawing on personal resilience, navigating two contrasting educational expectations, whilst relying on uncertain technological access to their home university.

\section{References}

Australian Association of Social Workers (AASW). (2010). Australian Social Work Education and Accreditation Standards (ASWEAS). Canberra: AASW.

Barlow, C.A. (2007). In the third space: a case study of Canadian students in a social work practicum in India. International Social Work, 50(2), 243-254.

Bartoli, A., Kennedy, S. \& Tedam, P. (2008). Practice learning: who is failing to adjust? Black African student experience of practice learning in a social work setting. Journal of Practice Teaching \& Learning. 8(2), 75-90.

Beecher, B., Eggertsen, L., Furuto, S. \& Reeves, J. (2012). International student views of social work in select Asian and Pacific Island countries. Social Work Education: The International Journal. 31(4), 435-450. 
Bell, K. \& Anscombe, A.W. (Bill). (2013). International field experience in social work: outcomes of a short-term study abroad programme to India. Social Work Education: The International Journal. 32(8), 1032-1047.

Boyle, D.P., Nackerud, L. \& Kilpatrick, A. (1999). The road less travelled: cross cultural, international experiential learning. International Social Work. 42(2), 201-214.

Cleak, H. \& Fox, M. (2011). Current Australian programs for international field placements. In C. Noble, \& M. Henrickson (Eds.). Social Work Field Education and Supervision Across Asia Pacific, (pp. 23-44). Sydney: Sydney University Press.

Cooper, L. \& Maidment, J. (2001). Thinking about difference in student supervision. Australian Social Work. 54(1), 41-52.

Cornelius, L.J. \& Greif, G.L. (2005). Schools of social work and the nature of their foreign collaborations. International Social Work. 48(6), 823-833.

Crisp, B. (2009). Is there a role for 'foreigners' as social work educators?. Social Work Education. 28(6), 668-677.

Das, C. \& Anand, J.C. (2014). Strategies for critical reflection in international contexts for social work students. International Social Work. 57(2),109-120.

Dominelli, L. \& Bernard, W. T. (Eds.). (2003). Broadening Horizons. Aldershot: Ashgate.

Dominelli, L. (2014). Internationalizing professional practices: The place of social work in the international arena. International Social Work. 57(3), 258267. 
Engstrom, D. \& Jones, L.P. (2007). A broadened horizon: the value of international social work internships. Social Work Education. 26(2),136-150.

Garrity, P. (2011). Australian social work students in Vietnam: the collision of cultural difference. In C. Noble \& M. Henrickson (Eds.). Social Work Field Education and Supervision across Asia Pacific, (pp. 115-144). Sydney: Sydney University Press.

Grace, M., Townsend, R. Testa, D., Fox, J., O'Maley, P., Custance, J. \& Daddow, A. (2013). Student diversity as grass roots internationalisation in social work education. Advances in Social Work \& Welfare Education. 15(1), 120-134.

Grant, L. \& Kinman, G. (2012). Enhancing wellbeing in social work students: building resilience in the next generation. Social Work Education. 31(5), 605621.

Gray, M. (2005). Dilemmas of international social work: paradoxical processes in indigenisation, universalism and imperialism. International Journal of Social Welfare. 14, 231-238.

Harrison, G. \& Ip, R. (2012). Extending the terrain of inclusive education in the classroom to the field: international students on placement. Social Work Education: The International Journal. 32(2), 230-243.

Healy, L. M. (2008). International Social Work: Professional Action in an Interdependent World. Oxford: Oxford University Press.

Hokenstad, M.C. \& Midgley, J. (1997). Realities of global interdependence: challenges for social work in a new century. In M.C. Hokenstad \& J. Midgley (Eds.). Issues in International Social Work: Global Challenges for a New Century, (pp. 1-11). Washington D.C.: NASW Press 
Hollinsworth, D. (2013). Forget cultural competence; ask for an autobiography. Social Work Education: The International Journal. 32(8), 10481060.

Holtzhausen, L. (2011). 'I am an Arab but I live in an English world': teaching social work in the United Arab Emirates. Journal of Social Work. 11(3), 268286.

Hugman, R. (2010). Understanding International Social Work: A Critical Analysis. London: Palgrave Macmillan.

Kleinpeter, C.B. \& Potts, M.K. (2004). Distance education evaluation: the second cohort. Professional Development. 7(1), 4-13.

Lyons, K., Manion, K. \& Carlsen, M. (2006). International Perspectives on Social Work: Global Conditions and Local Practice. Basingstoke and New York: Palgrave Macmillan.

Nadan, Y. \& Ben-Ari, A. (2013). What can we learn from rethinking 'multiculturalism' in social work education?. Social Work Education: The International Journal. 32(8), 1089-1102.

Nagy, G. \& Falk, D. (2000). Dilemmas in international and cross-cultural social work education. International Social Work. 43(1), 49-60.

Napier, L. (2006). Practising critical reflection. In A. O'Hara, \& Z. Weber (Eds.). Skills for Human Service Practice, (pp. 7-16). Melbourne: Oxford University Press.

Nickson, A., Kuruleca, S. \& Clarke, M. (2009). Fijian and Australian social work learning through field education. In C. Noble, M. Henrickson, \& I.Y. Han (Eds.). Social Work Education: Voices from the Asia Pacific, (pp. 50-71). Melbourne: The Vulgar Press. 
Noble, C., Henrickson, M. \& Han, I.Y. (2009). Social Work Education: Voices from the Asia Pacific. Melbourne: The Vulgar Press.

Noble, C. \& Henrickson, M. (2011). Social Work Field Education and Supervision across Asia Pacific. Sydney: Sydney University Press.

Panos, P.T. (2005). A model for using videoconferencing technology to support international social work field practicum students. International Social Work. 48(6), 834-841.

Pettys, G.L., Panos, P.T., Cox, S. \& Oosthuysen, K. (2005). Four models of international field placement. International Social Work. 48(3), 277-288.

Pullen-Sansfacon, A., Spolander, G. \& Engelbrecht, L. (2012). Migration of professional social workers: reflections on challenges and strategies for education. Social Work Education: The International Journal. 31(8), 10321045.

Quinn, M. (2009). Towards anti-racist and culturally affirming practices. In J. Allan, L. Briskman \& B. Pease (Eds.). Critical Social Work, (pp. 91-104). Sydney: Allen \& Unwin.

Rai, G.S. (2004). International fieldwork experience: a survey of US schools. International Social Work. 47(2), 213-226.

Razack, N. (2002). A critical examination of international student exchanges. International Social Work. 45(2), 251-265.

Romanov, P. \& Kononenko, R. (2014). Glocalization processes in Russian social work. International Social Work. 57(5), 435-446.

Rotabi, K.S., Gammonley, D. \& Gamble, D.N. (2006). Ethical guidelines for study abroad: can we transform ugly Americans into engaged global citizens?. British Journal of Social Work. 36, 451-465. 
Saito, Y. \& Johns, R. (2009). Japanese students' perceptions of international perspectives in social work. International Social Work. 52(1), 60-71.

Sewpaul, V. \& Jones, D. (2004). Global Standards for Social Work Education and Training. Social Work Education. 23(5), 493-513.

Stiglitz, J.E. (2007). Globalism's discontents (2002). In J.T. Roberts and A.B. Hite (Eds.). The Globalization and Development Reader: Perspectives on Development and Global Change, (pp. 295-304). Oxford: Blackwell Publications Ltd.

Tesoriero, F. \& Rajaratnam, A. (2001). Partnership in education: an Australian school of social work and a South Indian primary health care project. International Social Work. 44(1), 31-41.

Warde, B. (2012). The cultural genogram: enhancing the cultural competency of social work students. Social Work Education: The International Journal. 31(5), 570-586. 